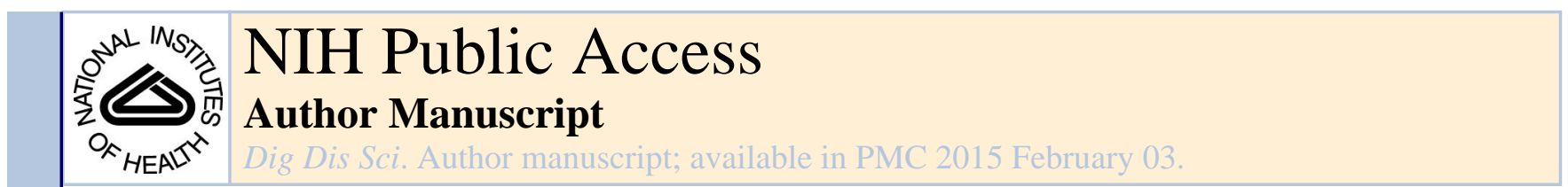

Published in final edited form as:

Dig Dis Sci. 2014 June ; 59(6): 1222-1230. doi:10.1007/s10620-014-3186-3.

\title{
Cost-Effectiveness of Chemoprevention with Proton Pump Inhibitors in Barrett's Esophagus
}

\author{
Reem Z. Sharaiha, \\ Division of Gastroenterology and Hepatology, Department of Medicine, Weill Cornell Medical \\ College, 1305 York Avenue, 4th Floor, New York, NY 10021, USA \\ Daniel E. Freedberg, \\ Division of Digestive and Liver Diseases, Columbia University Medical Center, 630 West 168th \\ Street, PH Building, 7th Floor, New York, NY 10032, USA \\ Julian A. Abrams, and \\ Division of Digestive and Liver Diseases, Columbia University Medical Center, 630 West 168th \\ Street, PH Building, 7th Floor, New York, NY 10032, USA \\ Y. Claire Wang \\ Department of Health Policy and Management, Mailman School of Public Health, 722 West 168th \\ Street, New York, NY 10032, USA
}

Reem Z. Sharaiha: rzs9001@med.cornell.edu; Daniel E. Freedberg: def2004@cumc.columbia.edu; Julian A. Abrams: ja660@cumc.columbia.edu; Y. Claire Wang: ycw2102@columbia.edu

\section{Abstract}

Background-Proton pump inhibitors (PPIs) may reduce the risk of esophageal adenocarcinoma (EAC) in patients with Barrett's esophagus. PPIs are prescribed for virtually all patients with Barrett's esophagus, irrespective of the presence of reflux symptoms, and represent a de facto chemopreventive agent in this population. However, long-term PPI use has been associated with several adverse effects, and the cost-effectiveness of chemoprevention with PPIs has not been evaluated.

Aim-The purpose of this study was to assess the cost-effectiveness of PPIs for the prevention of EAC in Barrett's esophagus without reflux.

Methods-We designed a state-transition Markov micro-simulation model of a hypothetical cohort of 50-year-old white men with Barrett's esophagus. We modeled chemoprevention with PPIs or no chemoprevention, with endoscopic surveillance for all treatment arms. Outcome measures were life-years, quality-adjusted life years (QALYs), incident EAC cases and deaths, costs, and incremental cost-effectiveness ratios.

(C) Springer Science+Business Media New York 2014

Correspondence to: Reem Z. Sharaiha, rzs9001@med.cornell .edu.

Electronic supplementary material The online version of this article (doi:10.1007/s10620-014-3186-3) contains supplementary material, which is available to authorized users.

Conflict of interest None. 
Results-Assuming $50 \%$ reduction in EAC, chemoprevention with PPIs was a cost-effective strategy compared to no chemoprevention. In our model, administration of PPIs cost $\$ 23,000$ per patient and resulted in a gain of 0.32 QALYs for an incremental cost-effectiveness ratio of $\$ 12,000 / \mathrm{Q} A L Y$. In sensitivity analyses, PPIs would be cost-effective at $\$ 50,000 / \mathrm{QALY}$ if they reduce EAC risk by at least $19 \%$.

Conclusions-Chemoprevention with PPIs in patients with Barrett's esophagus without reflux is cost-effective if PPIs reduce EAC by a minimum of $19 \%$. The identification of subgroups of Barrett's esophagus patients at increased risk for progression would lead to more cost-effective strategies for the prevention of esophageal adenocarcinoma.

\section{Keywords}

Cost-effectiveness; Proton pump inhibitors; Barrett's esophagus; Esophageal adenocarcinoma; Clostridium difficile infection; Pharmacoepidemiology; Chemoprevention

\section{Introduction}

The incidence of esophageal adenocarcinoma (EAC) has risen dramatically over the past four decades in western countries [1,2]. The prognosis of this cancer remains extremely poor, with a 5-year survival rate of $16 \%$ in the United States [3]. Barrett's esophagus (BE) is the established precursor to $\mathrm{EAC}$, and the rate of progression of $\mathrm{BE}$ to adenocarcinoma is $0.1-0.5 \%$ per year [4-7]. One of the mainstays of BE management is regular endoscopic surveillance [8]. The aim of surveillance is to identify patients at a preclinical or asymptomatic early stage of cancer and initiate treatment leading to improved long-term outcomes. However, it is unclear whether surveillance alone leads to reduced mortality from EAC [9].

In light of the poor outcomes associated with EAC, combined with the presence of a readily identifiable precursor lesion, Barrett's esophagus represents an attractive target for chemoprevention. Because the absolute risk of EAC is very low even in BE patients [4-6], a viable chemoprevention strategy would have to be safe, inexpensive, and effective. Gastroesophageal reflux (GERD) is a primary risk factor for EAC [10], and several epidemiologic studies suggest that gastric acid suppression with proton pump inhibitors (PPIs) has chemopreventive effects in patients with BE [11-14]. A recent meta-analysis of these studies reported that PPI use in BE patients was associated with a $71 \%$ reduced risk of progression to high-grade dysplasia (HGD) or EAC [15]. While clinical guidelines do not formally recommend gastric acid suppression as a means of cancer risk reduction for patients with BE, in clinical practice, PPIs have become a de facto chemopreventive agent [16]. Currently, between 95 and $98 \%$ of patients with BE are prescribed PPIs [4, 17]. However, 30-50\% of BE patients do not have regular reflux symptoms yet are still prescribed PPIs [18-22]. Furthermore, novel, less invasive diagnostic techniques for BE such as a cytological sponge or transnasal endoscopy have the potential to increase the proportion of asymptomatic BE patients [23, 24].

Proton pump inhibitors (PPIs) have historically been considered safe medications. However, recent observational data suggest that chronic PPI use is associated with increased risks of 
bone fractures and of Clostridium difficile infection [25-29]. Based on these data, the Food and Drug Administration has issued warnings regarding long-term PPIs and bone fracture and PPIs and $C$. difficile infection [30,31]. Despite these concerns, practitioners continue to prescribe PPIs to virtually all BE patients. To date, no formal quantitative analysis has been published to support the use of PPIs for the prevention of EAC. We therefore constructed a decision-analytic model to weigh the benefit of PPIs against their adverse effects and to evaluate the cost-effectiveness of PPIs as chemoprevention for EAC in BE patients without GERD. Using this model, we determined the threshold for the efficacy of PPIs to be costeffective at common cost-effectiveness benchmarks and, assuming $50 \%$ efficacy in reducing progression of $\mathrm{BE}$, the incremental cost-effectiveness ratio for PPIs.

\section{Methods}

\section{Patient Population and Time Frame}

We modeled a hypothetical cohort of 250,000 50-year-old white men newly diagnosed with non-dysplastic BE at baseline until they reached age 80 or died, whichever occurred first. This cohort was chosen because white men of this age range represent the demographic most at risk for EAC [1]. Non-dysplastic BE was defined by both the American College of Gastroenterology and the American Gastroenterological Association definitions of endoscopically suspected Barrett's esophagus combined with the presence of intestinal metaplasia on esophageal biopsies $[8,32]$. This study was approved by the institutional review board of Columbia University.

\section{Strategies}

We modeled two different strategies: no chemoprevention (comparator) and chemoprevention with PPIs. Endoscopic surveillance represents the current standard of care for BE [8] and was incorporated into all of the strategies. All patients in the PPI chemoprevention arm received a oncedaily dose of PPI. While a recent meta-analysis reported that PPI use is associated with a $71 \%$ reduction in the risk of HGD or EAC in BE patients [15], we chose a more conservative $50 \%$ risk reduction for EAC and varied this estimate widely $(0-100 \%)$ in the sensitivity analysis.

In our analysis, we assumed that patients without dysplasia would undergo endoscopic surveillance every three years and patients with low-grade dysplasia every year until no dysplasia was detected [8]. Patients with highgrade dysplasia underwent radiofrequency ablation, now endorsed as a preferred management strategy [32]. Successful ablation was followed by an endoscopy four times a year in the first year, twice in the following year, and then yearly thereafter. This schedule was derived from recent guidelines [32,33] as well as from the post-ablation protocol from the AIM-Dysplasia Trial of radiofrequency ablation for BE with low- and high-grade dysplasia [34]. For all patients, endoscopic surveillance continued until reaching 80 years of age or death. If EAC was diagnosed, patients were considered for surgical resection; we assumed that $15 \%$ of these cases would be unresectable $[35,36]$ and that patients would then undergo palliative therapy. 


\section{Markov Model}

A state-transition Markov microsimulation model (TreeAge Pro 2011, Williamstown, MA) was constructed to simulate the disease progression, outcomes, and costs incurred under each strategy. At the end of each annual cycle, each simulated patient faced a probability of transition to another state (Fig. 1). All patients started in the BE without dysplasia state at baseline. Each state was assigned a state-specific cost and utility per year. The model also included events such as surgical mortality, morbidity from both radiofrequency ablation (RFA) and surgery, and risk of recurrent cancer.

Transition probabilities, cost, and utility weights were obtained from the published literature (Table 1). In our base case, a $50 \%$ reduction in the risk of EAC was assumed for patients who received PPIs. The model included the two primary adverse effects of PPI use: increased risk of bone fractures and increased risk of $C$. difficile infection. In the PPI strategy, the rate of bone fracture was assumed to increase after 2 years of use; increase in $C$. difficile infection, on the other hand, was assumed to occur from the outset. The model also considered that a proportion of community-acquired $C$. difficile cases would result in hospitalization [37, 38]. Mortality from EAC and from other causes was derived from the Surveillance, Epidemiology, and End Results (SEER) database, adjusted for age and sex [39].

Costs were analyzed from the third-party payers' perspective. Only direct medical costs were considered, and all costs were expressed in 2011 US dollars [40]. Procedure costs were estimated based on the 2011 national average Medicare reimbursement rate [41] and included the cost of the procedure as well as professional and facility fees [41, 42]. Medication costs were derived from the Pharmacy Redbook and Internet retail sources, based on the average Redbook pricing for generic omeprazole $20 \mathrm{mg}$ daily [43]. Treatment costs for fracture and $C$. difficile management were taken from the published literature [44, 45]. Utility weights for health states and events were directed from the literature, ranging from 1 (perfect health) to 0 (death). These weights were aggregated to estimate qualityadjusted life years (QALYs) for each modeled patient under different clinical strategies [46].

\section{Cost-Effectiveness Analysis}

The primary outcome of the study was the incremental cost per QALY gained, also known as the incremental cost-effectiveness ratio (ICER). The ICER is calculated by dividing the difference in costs by the difference in average QALY between the two strategies. Both costs and QALYs were discounted at an annual rate of $3 \%$ [46]. We evaluated the ICER on two often-cited benchmark willingness-to-pay levels: \$50,000/QALY and \$100,000/QALY.

\section{Sensitivity Analysis}

Sensitivity analyses were performed to investigate the effects of parameter uncertainties on the resulting cost and effectiveness outcomes [46]. Probabilistic sensitivity analysis was performed by simultaneously and probabilistically varying costs, probabilities, quality of life weights, and discount rates. Ranges were based on published $95 \%$ confidence intervals (CIs); in their absence, we varied the parameter from 50 to $200 \%$ of its base-case value. 


\section{Results \\ Base-Case Results}

Consistent with previously published estimates [47, 48], our model estimated a $5.6 \%$ lifetime risk of EAC for this non-dysplastic BE cohort with an average life expectancy of 19.5 years. In the absence of chemoprevention, 14,000 esophageal adenocarcinomas were expected to develop among the simulated 250,000 50-year-old patients with non-dysplastic $\mathrm{BE}$ who received the current standard of care with endoscopic surveillance. Use of PPIs proved to be a cost-effective strategy. Administration of PPIs as chemoprevention resulted in a gain of 0.32 QALYs at a total cost of $\$ 23,495$ per patient, with an ICER of $\$ 11,760$ per QALY (Table 2). Greater than $95 \%$ of the simulations showed that the strategy that involved PPIs was the most cost-effective at \$50,000/QALY (Fig. 2).

\section{Minimum Cost-Effective Chemopreventive Effect}

Proton pump inhibitors (PPIs) remained cost-effective if they reduced EAC risk by $\geq 19 \%$ at $\$ 50,000 / \mathrm{QALY}$ and by $\geq 11 \%$ at $\$ 100,000 / \mathrm{QALY}$ (Fig. 3). For lower effectiveness of PPIs in preventing EAC, surveillance alone represented the dominant strategy. Under our base-case assumptions, PPIs remained cost-effective up to an annual cost of $\$ 940$ at $\$ 50,000 / \mathrm{QALY}$ and $\$ 1,660$ for $\$ 100,000$ / QALY (Supplemental Figure 1).

\section{Discussion}

Our study shows that chemoprevention with proton pump inhibitors for patients with Barrett's esophagus without GERD could provide significant risk reduction in esophageal adenocarcinoma with acceptable costs. The incidence of EAC has been rising rapidly for the past four decades [1,2], and interventions to lower the risk of EAC have the potential for a major impact at the population level. Our Markov model's base case assumed a $50 \%$ reduction in EAC risk for patients who received PPIs. This assumption correlated to an absolute $3.3 \%$ reduction in lifetime EAC risk among patients with non-dysplastic BE. Although the absolute risk of neoplastic progression in BE is low [4-6, 49-51], our model indicates that PPIs are cost-effective in asymptomatic BE patients as long as the drugs remain inexpensive and current estimates of PPI-related risks remain unchanged. Our results lend support to the current practice of prescribing PPI therapy to all patients with BE, irrespective of the presence of acid reflux symptoms.

In order to appropriately interpret the significance of these findings, one must consider the variable clinical presentation of patients with BE. Many patients with BE have chronic reflux symptoms; PPIs have obvious therapeutic value in this group and therefore have benefits beyond potential EAC risk reduction. However, in two studies aimed at determining BE prevalence, 44-54\% of Barrett's patients denied a history of regular reflux symptoms $[21,22]$, and the results of a meta-analysis found no association between GERD and shortsegment BE [52]. Despite this, recent cohort studies report that $95-98 \%$ of BE patients under surveillance are prescribed PPIs $[4,53]$. This discrepancy is due to the belief among physicians that acid suppression may reduce the risk of progression to EAC [54]. 
What is the evidence that acid suppression with PPIs prevents EAC? While clinical trial data are lacking, epi-demiologic studies suggest that PPI use in patients with BE has chemopreventive effects [12-14, 55]. In a study by El-Serag et al. [13] of veterans with BE, PPI use (compared to histamine-2 antagonists and no acid suppression) had a lower risk of progression to dysplasia (HR $0.25,95 \%$ CI $0.13-0.47$ ). In a case-control study from the Netherlands, patients with EAC were less likely to have used PPIs (OR 0.1, $95 \%$ CI 0.050.2 ) compared to BE patients with no dysplasia or low-grade dysplasia [14]. A recent metaanalysis including data from 2,813 patients with BE concluded that PPI use was associated with a $71 \%$ decreased risk of progression to EAC or high-grade dysplasia [15]. Laboratory data also suggest that gastric acid reflux promotes cancer in BE via increased cellular proliferation and decreased apoptosis [56-58].

Our model demonstrates that PPIs must prevent $19 \%$ of EACs in order to remain costeffective. This moderately low threshold for efficacy is driven largely by the low cost of generic PPIs. Prior to the FDA approval of generic omeprazole in 2002, the cost of brand PPIs was roughly $\$ 1,000-1,500$ per year [59]. PPIs at this cost would have needed to prevent $60-80 \%$ of EACs to remain a cost-effective strategy. Therefore, market cost is a key factor in the evaluation of any chemopreventive drug in BE, including PPIs. Other potential chemopreventive agents that have been studied or are currently under investigation for BE include celecoxib, aspirin, difluoromethylornithine, green tea extract, cholestyramine, and a gastrin-receptor inhibitor [60-63]. A new drug on patent will likely be associated with significant costs and will need to be extremely effective at preventing EAC to achieve standard benchmarks of cost-effectiveness.

The decision-analytic model in the present study was sensitive to both PPI efficacy and costs, both of drug and of adverse effects. The model included the two adverse effects of PPI use for which the best evidence exists: increased risks of bone fractures and of $C$. difficile infection. The association between PPIs and incident $C$. difficile infection is well established $[64,65]$ while the association between PPIs and bone fracture is more controversial $[25,66]$. When the analysis was performed without incorporation of adverse effects, PPIs were costeffective for risk reductions as low as $2 \%$ (data not shown). Should additional adverse effects of long-term PPI use be discovered, then the minimum chemopreventive efficacy required for PPIs to remain cost-effective will increase.

Currently, all patients with non-dysplastic BE are treated with a "one-size-fits-all" approach. However, the risk of developing EAC is extremely low, which limits the cost-effectiveness of any strategy aimed at improving outcomes in this population. If the transition rates in the model are markedly increased, for example through the identification of a BE subgroup at high risk for progression, then the minimum required chemopreventive efficacy is substantially reduced. In the future, chemoprevention targeted to high-risk subgroups in which a particular agent provides maximal benefit will likely represent the optimal management strategy. Conversely, patients at lower risk to progress would derive the least benefit from chemoprevention.

Prior studies have examined the cost-effectiveness of chemoprevention in Barrett's esophagus. All models must rely upon contemporaneous data, and transitional probabilities 
for progression of $\mathrm{BE}$ have decreased over time while drug cost estimates have simultaneously fallen. Sonnenberg and Fennerty [67] used Markov modeling to show that NSAID use without endoscopic surveillance was a cost-effective strategy. For patients with non-dys-plastic BE, the disease states consisted of BE, EAC, post-esophagectomy, or death, with dysplasia and endoscopic therapy not included in the model. When progression rates were reduced below $0.5 \%$ per year in sensitivity analyses, chemoprophylaxis became prohibitively expensive. This is relevant given recent cohort studies suggesting that the rate of progression from BE to EAC may be closer to $0.1-0.3 \%$ per year [4-6, 49-51], rather than the traditionally cited $0.5 \%$ per year [7]. Hur et al. evaluated the cost-effectiveness of aspirin for the prevention of EAC [47]. This model included dysplastic states, and all patients with high-grade dysplasia were considered for esophagectomy. Aspirin was assigned a base efficacy of $50 \%$ EAC risk reduction, and hemor-rhagic complications of aspirin were included in the model. The analyses showed that aspirin with and without endoscopic surveillance represented cost-effective strategies. Choi et al. [68] also recently demonstrated that chemoprevention with aspirin could be a cost-effective strategy when added to endoscopic surveillance for non-dysplastic BE, with a base-case assumption of 50 $\%$ reduction in EAC incidence with aspirin. Finally, comprehensive cost-effectiveness analyses of radiofrequency ablation show that RFA is a cost-effective strategy in dysplastic $\mathrm{BE}$, although the strategy of RFA for non-dysplastic BE remains controversial [48, 69].

Our study has several strengths. Our model included the two primary major adverse effects of PPIs: increased risks of bone fractures and of $C$. difficile infection. These adverse effects play a key role in the clinical decision to prescribe long-term PPIs for the purpose of chemoprevention in BE. Because endoscopic surveillance currently represents the standard of care in BE, surveillance was incorporated into all arms of the study unlike prior models. Endoscopic therapy has been endorsed as the preferred management strategy for high-grade dysplasia [32] and was made a standard element in our model. Our model expands on prior work, incorporates recent data on progression rates for non-dysplastic BE, and uses recently published post-RFA utility data. Finally, our model uses sensitivity analyses to determine optimal cutoffs within categories and utility estimates based on the observed data among BE patients rather than on physician estimates. Although our model requires assumptions regarding the efficacy of chemoprevention with PPIs, our study is the first of its kind to provide evidence supporting the clinical practice of prescribing PPIs to patients with nondysplastic BE without reflux.

The current analyses have some limitations. Our model data are drawn primarily from US sources, and our model may not be generalizable to other populations. In the construction of the model, a $50 \%$ EAC risk reduction was assigned for PPIs. However, there is no clinical trial data on which to base this estimate, and epidemiologic data suffer from potential confounding by indication as well as by variable compliance rates. This underlying uncertainty was accounted for by varying the effect from 0 to $100 \%$ in the sensitivity analyses. The model did not include disease regression (other than LGD to no dysplasia) or misdiagnosis because these factors would impact all study arms in a comparable fashion. Furthermore, the impact of these factors would likely have been relatively small, and our 
model produced lifetime incidence rates of EAC comparable to other models and to estimates in humans [4, 48].

Our study shows that the use of PPIs in patients with Barrett's esophagus without reflux symptoms represents a cost-effective strategy for the prevention of esophageal adenocarcinoma and demonstrates that PPIs remain cost-effective at \$50,000/QALY provided that they attain a minimum efficacy in preventing progression to EAC of $19 \%$. Our model was sensitive to rates of progression, efficacy of PPIs, and costs associated with adverse effects of PPIs. Clinical trial data are needed to better estimate the efficacy of PPIs or other chemopreventive agents in patients with Barrett's esophagus. Future studies should identify subgroups of Barrett's esophagus patients at increased risk for progression to facilitate risk-stratified management strategies including chemoprevention.

\section{Supplementary Material}

Refer to Web version on PubMed Central for supplementary material.

\section{Acknowledgments}

Dr. Sharaiha was supported by a training grant from the National Cancer Institute (T32 CA009529). Dr. Freedberg is supported in part by a training grant from the National Institute of Diabetes and Digestive and Kidney Diseases (T32 DK083256-04). Dr. Abrams was supported in part by a Career Development Award from the National Cancer Institute (K07 CA132892). This publication was also supported in part by the National Center for Research Resources and the National Center for Advancing Translational Sciences, National Institutes of Health, through Grant Number UL1 RR024156.

\section{References}

1. Brown LM, Devesa SS, Chow WH. Incidence of adenocarcinoma of the esophagus among white Americans by sex, stage, and age. J Natl Cancer Inst. 2008; 100:1184-1187. [PubMed: 18695138]

2. Abrams JA, Sharaiha RZ, Gonsalves L, et al. Dating the rise of esophageal adenocarcinoma: analysis of Connecticut Tumor Registry data, 1940-2007. Cancer Epidemiol Biomarkers Prev. 2011; 20:183-186. [PubMed: 21127287]

3. Jemal A, Siegel R, Xu J, et al. Cancer statistics, 2010. CA Cancer J Clin. 2010; 60:277-300. [PubMed: 20610543]

4. Wani S, Falk G, Hall M, et al. Patients with nondysplastic Barrett's esophagus have low risks for developing dysplasia or esophageal adenocarcinoma. Clin Gastroenterol Hepatol. 2011; 9:220-227. quiz e26. [PubMed: 21115133]

5. Hvid-Jensen F, Pedersen L, Drewes AM, et al. Incidence of adenocarcinoma among patients with Barrett's esophagus. N Engl J Med. 2011; 365:1375-1383. [PubMed: 21995385]

6. Bhat S, Coleman HG, Yousef F, et al. Risk of malignant progression in Barrett's esophagus patients: results from a large population-based study. J Natl Cancer Inst. 2011; 103:1049-1057. [PubMed: 21680910]

7. Shaheen NJ, Crosby MA, Bozymski EM, et al. Is there publication bias in the reporting of cancer risk in Barrett's esophagus? Gastroenterology. 2000; 119:333-338. [PubMed: 10930368]

8. Wang KK, Sampliner RE. Updated guidelines 2008 for the diagnosis, surveillance and therapy of Barrett's esophagus. Am J Gastroenterol. 2008; 103:788-797. [PubMed: 18341497]

9. Corley DA, Mehtani K, Quesenberry C, et al. Impact of endo-scopic surveillance on mortality from Barrett's esophagus-associated esophageal adenocarcinomas. Gastroenterology. 2013; 145312 e1$319 \mathrm{e} 1$.

10. Lagergren J, Bergstrom R, Lindgren A, et al. Symptomatic gas-troesophageal reflux as a risk factor for esophageal adenocarcinoma. N Engl J Med. 1999; 340:825-831. [PubMed: 10080844] 
11. Jung KW, Talley NJ, Romero Y, et al. Epidemiology and natural history of intestinal metaplasia of the gastroesophageal junction and Barrett's esophagus: a population-based study. Am J Gastroenterol. 2011; 106:1447-1455. quiz 1456.

12. Hillman LC, Chiragakis L, Shadbolt B, et al. Effect of proton pump inhibitors on markers of risk for high-grade dysplasia and oesophageal cancer in Barrett's oesophagus. Aliment Pharmacol Ther. 2008; 27:321-326. [PubMed: 18047565]

13. El-Serag HB, Aguirre TV, Davis S, et al. Proton pump inhibitors are associated with reduced incidence of dysplasia in Barrett's esophagus. Am J Gastroenterol. 2004; 99:1877-1883. [PubMed: 15447744]

14. de Jonge PJ, Steyerberg EW, Kuipers EJ, et al. Risk factors for the development of esophageal adenocarcinoma in Barrett's esophagus. Am J Gastroenterol. 2006; 101:1421-1429. [PubMed: 16863542]

15. Singh S, Garg SK, Singh PP, et al. Acid-suppressive medications and risk of oesophageal adenocarcinoma in patients with Barrett's oesophagus: a systematic review and meta-analysis. Gut. 2013

16. Spechler SJ. Barrett esophagus and risk of esophageal cancer: a clinical review. JAMA. 2013; 310:627-636. [PubMed: 23942681]

17. Nguyen DM, Richardson P, El-Serag HB. Medications (NSAIDs, statins, proton pump inhibitors) and the risk of esophageal ade-nocarcinoma in patients with Barrett's esophagus. Gastroenterology. 2010; 138:2260-2266. [PubMed: 20188100]

18. Veldhuyzen van Zanten SJ, Thomson AB, Barkun AN, et al. The prevalence of Barrett's oesophagus in a cohort of 1040 Canadian primary care patients with uninvestigated dyspepsia undergoing prompt endoscopy. Aliment Pharmacol Ther. 2006; 23:595-599. [PubMed: 16480398]

19. Voutilainen M, Sipponen P, Mecklin JP, et al. Gastroesophageal reflux disease: prevalence, clinical, endoscopic and histopathological findings in 1,128 consecutive patients referred for endos-copy due to dyspeptic and reflux symptoms. Digestion. 2000; 61:6-13. [PubMed: 10671769]

20. Abrams JA, Fields S, Lightdale CJ, et al. Racial and ethnic disparities in the prevalence of Barrett's esophagus among patients who undergo upper endoscopy. Clin Gastroenterol Hepatol. 2008; 6:30-34. [PubMed: 18063419]

21. Ronkainen J, Aro P, Storskrubb T, et al. Prevalence of Barrett's esophagus in the general population: an endoscopic study. Gas-troenterology. 2005; 129:1825-1831.

22. Rex DK, Cummings OW, Shaw M, et al. Screening for Barrett's esophagus in colonoscopy patients with and without heartburn. Gastroenterology. 2003; 125:1670-1677. [PubMed: 14724819]

23. Peery AF, Hoppo T, Garman KS, et al. Feasibility, safety, acceptability, and yield of office-based, screening transnasal esophagoscopy (with video). Gastrointest Endosc. 2012; 75:945-953. [PubMed: 22425272]

24. Kadri SR, Lao-Sirieix P, O’Donovan M, et al. Acceptability and accuracy of a non-endoscopic screening test for Barrett's oesophagus in primary care: cohort study. BMJ. 2010; 341:c4372. [PubMed: 20833740]

25. Yang YX, Lewis JD, Epstein S, et al. Long-term proton pump inhibitor therapy and risk of hip fracture. JAMA. 2006; 296:2947-2953. [PubMed: 17190895]

26. Dial S, Delaney JA, Barkun AN, et al. Use of gastric acid-suppressive agents and the risk of community-acquired Clostridium difficile-associated disease. JAMA. 2005; 294:2989-2995. [PubMed: 16414946]

27. Gray SL, LaCroix AZ, Larson J, et al. Proton pump inhibitor use, hip fracture, and change in bone mineral density in postmeno-pausal women: results from the Women's Health Initiative. Arch Intern Med. 2010; 170:765-771. [PubMed: 20458083]

28. Corley DA, Kubo A, Zhao W, et al. Proton pump inhibitors and histamine-2 receptor antagonists are associated with hip fractures among at-risk patients. Gastroenterology. 2010; 139:93-101. [PubMed: 20353792]

29. Loo VG, Bourgault AM, Poirier L, et al. Host and pathogen factors for Clostridium difficile infection and colonization. N Engl J Med. 2011; 365:1693-1703. [PubMed: 22047560] 
30. Food and Drug Administration. [Accessed October 15, 2013] U.S. Department of Health and Human Services. http://www.fda.gov/drugs/drugsafety/ postmarketdrugsafetyinformationforpatientsandproviders/ucm213206.htm

31. Food and Drug Administration. [Accessed October 15, 2013] U.S. Department of Health and Human Services. http://www.fda.gov/drugs/drugsafety/ucm290510.htm

32. Spechler SJ, Sharma P, Souza RF, et al. American Gastroentero-logical Association medical position statement on the management of Barrett's esophagus. Gastroenterology. 2011; 140:10841091. [PubMed: 21376940]

33. Spechler SJ, Sharma P, Souza RF, et al. American Gastroenter-ological Association technical review on the management of Barrett's esophagus. Gastroenterology. 2011; 140:e18-e52. (quiz e13). [PubMed: 21376939]

34. Shaheen NJ, Sharma P, Overholt BF, et al. Radiofrequency ablation in Barrett's esophagus with dysplasia. N Engl J Med. 2009; 360:2277-2288. [PubMed: 19474425]

35. Streitz JM Jr, Andrews CW Jr, Ellis FH Jr. Endoscopic surveillance of Barrett's esophagus Does it help? J Thorac Cardiovasc Surg. 1993; 105:383-387. [PubMed: 8445916]

36. Corley DA, Levin TR, Habel LA, et al. Surveillance and survival in Barrett's adenocarcinomas: a population-based study. Gastroenterology. 2002; 122:633-640. [PubMed: 11874995]

37. Khanna S, Pardi DS, Aronson SL, et al. The epidemiology of community-acquired Clostridium difficile infection: a population-based study. Am J Gastroenterol. 2012; 107:89-95. [PubMed: 22108454]

38. Chitnis AS, Holzbauer SM, Belflower RM, et al. Epidemiology of community-associated Clostridium difficile infection, 2009 through 2011. JAMA Intern Med. 2013; 173:1359-1367. [PubMed: 23780507]

39. National Cancer Institute. [Accessed October 15, 2013] Surveillance Epidemiology and End Results. http://seer.cancer.gov/

40. Gold M. Panel on cost-effectiveness in health and medicine. Med Care. 1996; 34:197-199.

41. Centers for Medicare and Medicaid Services. [Accessed October 15, 2013] Physician Fee Schedule Search. http://www.cms.gov/apps/physician-fee-schedule/

42. Physician Fee Schedule Look-up. [Accessed September 1, 2011] Available from: https:// www.cms.gov/

43. Roberts KJ, Harper E, Alderson D, et al. Long-term survival and cost analysis of an annual Barrett's surveillance programme. Eur J Gastroenterol Hepatol. 2010; 22:399-403. [PubMed: 19858726]

44. Liu H, Michaud K, Nayak S, et al. The cost-effectiveness of therapy with teriparatide and alendronate in women with severe osteoporosis. Arch Intern Med. 2006; 166:1209-1217. [PubMed: 16772249]

45. Lee BY, Popovich MJ, Tian Y, et al. The potential value of Clostridium difficile vaccine: an economic computer simulation model. Vaccine. 2010; 28:5245-5253. [PubMed: 20541582]

46. Hunink, M.; Glasziou, P. Decision Making in Health and Medicine: Integrating Evidence and Values. Cambridge: Cambridge University Press; 2001.

47. Hur C, Nishioka NS, Gazelle GS. Cost-effectiveness of aspirin chemoprevention for Barrett's esophagus. J Natl Cancer Inst. 2004; 96:316-325. [PubMed: 14970280]

48. Inadomi JM, Somsouk M, Madanick RD, et al. A cost-utility analysis of ablative therapy for Barrett's esophagus. Gastroen-terology. 2009; 1362101 e1-6-2114 e1-6.

49. Gordon LG, Mayne GC, Hirst NG, et al. Cost-effectiveness of endoscopic surveillance of nondysplastic Barrett's esophagus. Gastrointest Endosc. 2013; 79:242-256. [PubMed: 24079411]

50. Desai TK, Krishnan K, Samala N, et al. The incidence of oesophageal adenocarcinoma in nondysplastic Barrett's oesophagus: a meta-analysis. Gut. 2012; 61:970-976. [PubMed: 21997553]

51. Kastelein F, Spaander MC, Steyerberg EW, et al. Proton pump inhibitors reduce the risk of neoplastic progression in patients with Barrett's esophagus. Clin Gastroenterol Hepatol. 2013; 11:382-388. [PubMed: 23200977] 
52. Taylor JB, Rubenstein JH. Meta-analyses of the effect of symptoms of gastroesophageal reflux on the risk of Barrett's esophagus. Am J Gastroenterol. 2010; 105:1729. 1730-7; quiz 1738. [PubMed: 20485283]

53. Laroui H, Dalmasso G, Nguyen HT, et al. Drug-loaded nano-particles targeted to the colon with polysaccharide hydrogel reduce colitis in a mouse model. Gastroenterology. 2010; 138 843e1-2-853e1-2.

54. Chey WD, Inadomi JM, Booher AM, et al. Primary-care physicians' perceptions and practices on the management of GERD: results of a national survey. Am J Gastroenterol. 2005; 100:12371242. [PubMed: 15929751]

55. Hillman LC, Chiragakis L, Shadbolt B, et al. Proton-pump inhibitor therapy and the development of dysplasia in patients with Barrett's oesophagus. Med J Aust. 2004; 180:387-391. [PubMed: 15089728]

56. Fitzgerald RC, Omary MB, Triadafilopoulos G. Dynamic effects of acid on Barrett's esophagus An ex vivo proliferation and differentiation model. J Clin Invest. 1996; 98:2120-2128. [PubMed: 8903332]

57. Souza RF, Shewmake K, Terada LS, et al. Acid exposure activates the mitogen-activated protein kinase pathways in Barrett's esophagus. Gastroenterology. 2002; 122:299-307. [PubMed: 11832445]

58. Souza RF, Shewmake K, Pearson S, et al. Acid increases proliferation via ERK and p38 MAPKmediated increases in cyclooxygenase-2 in Barrett's adenocarcinoma cells. Am J Physiol Gastrointest Liver Physiol. 2004; 287:G743-G748. [PubMed: 15231484]

59. Drug Topics. 2001 Red Book. Montvale, NJ: PDR Network, LLC; 2001.

60. Heath EI, Canto MI, Piantadosi S, et al. Secondary chemoprevention of Barrett's esophagus with celecoxib: results of a randomized trial. J Natl Cancer Inst. 2007; 99:545-557. [PubMed: 17405999]

61. Abrams JA. Chemoprevention of esophageal adenocarcinoma. Therap Adv Gastroenterol. 2008; 1:7-18.

62. Sinicrope FA, Broaddus R, Joshi N, et al. Evaluation of difluo-romethylornithine for the chemoprevention of Barrett's esophagus and mucosal dysplasia. Cancer Prev Res (Phila). 2011; 4:829-839. [PubMed: 21636549]

63. Jankowski J, Moayyedi P. Re: cost-effectiveness of aspirin che-moprevention for Barrett's esophagus. J Natl Cancer Inst. 2004; 96:885-887. (author reply 887). [PubMed: 15173278]

64. Kwok CS, Arthur AK, Anibueze CI, et al. Risk of Clostridium difficile infection with acid suppressing drugs and antibiotics: meta-analysis. Am J Gastroenterol. 2012; 107:1011-1019. [PubMed: 22525304]

65. Janarthanan S, Ditah I, Adler DG, et al. Clostridium difficile-associated diarrhea and proton pump inhibitor therapy: a meta-analysis. Am J Gastroenterol. 2012; 107:1001-1010. [PubMed: 22710578]

66. Targownik LE, Leslie WD, Davison KS, et al. The relationship between proton pump inhibitor use and longitudinal change in bone mineral density: a population-based study [corrected] from the Canadian Multicentre Osteoporosis Study (CaMos). Am J Gastroenterol. 2012; 107:1361-1369. [PubMed: 22777336]

67. Sonnenberg A, Fennerty MB. Medical decision analysis of chemoprevention against esophageal adenocarcinoma. Gastroenterology. 2003; 124:1758-1766. [PubMed: 12806608]

68. Choi SE, Perzan K, Tramontano AC, et al. Statins and aspirin for chemoprevention in Barrett's esophagus: results of a cost-effectiveness analysis. Cancer Prev Res (Phila). 2014; 7:341-350. [PubMed: 24380852]

69. Hur C, Choi SE, Rubenstein JH, et al. The cost effectiveness of radiofrequency ablation for Barrett's esophagus. Gastroenterology. 2012; 143:567-575. [PubMed: 22626608] 


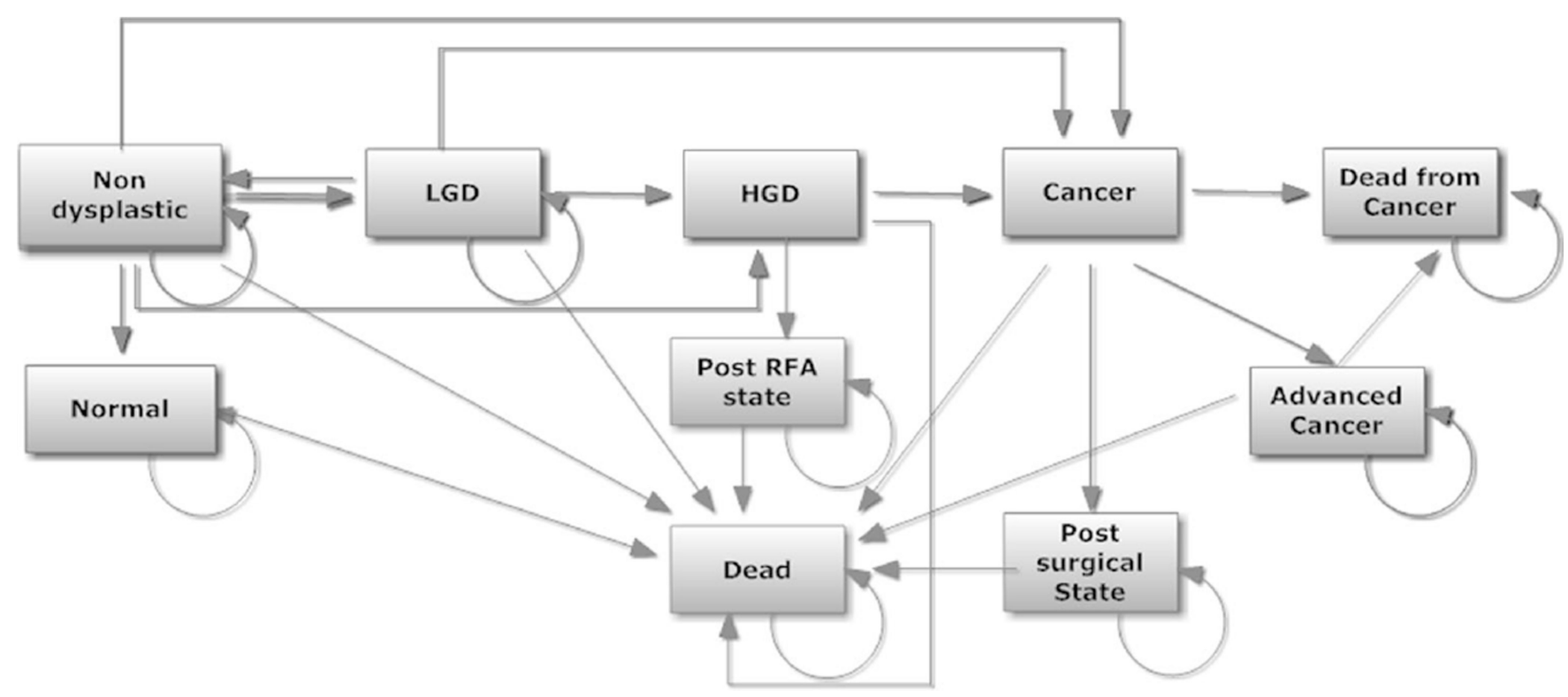

Fig. 1.

Markov model, with the various health and disease states, each associated with a different set of utilities 


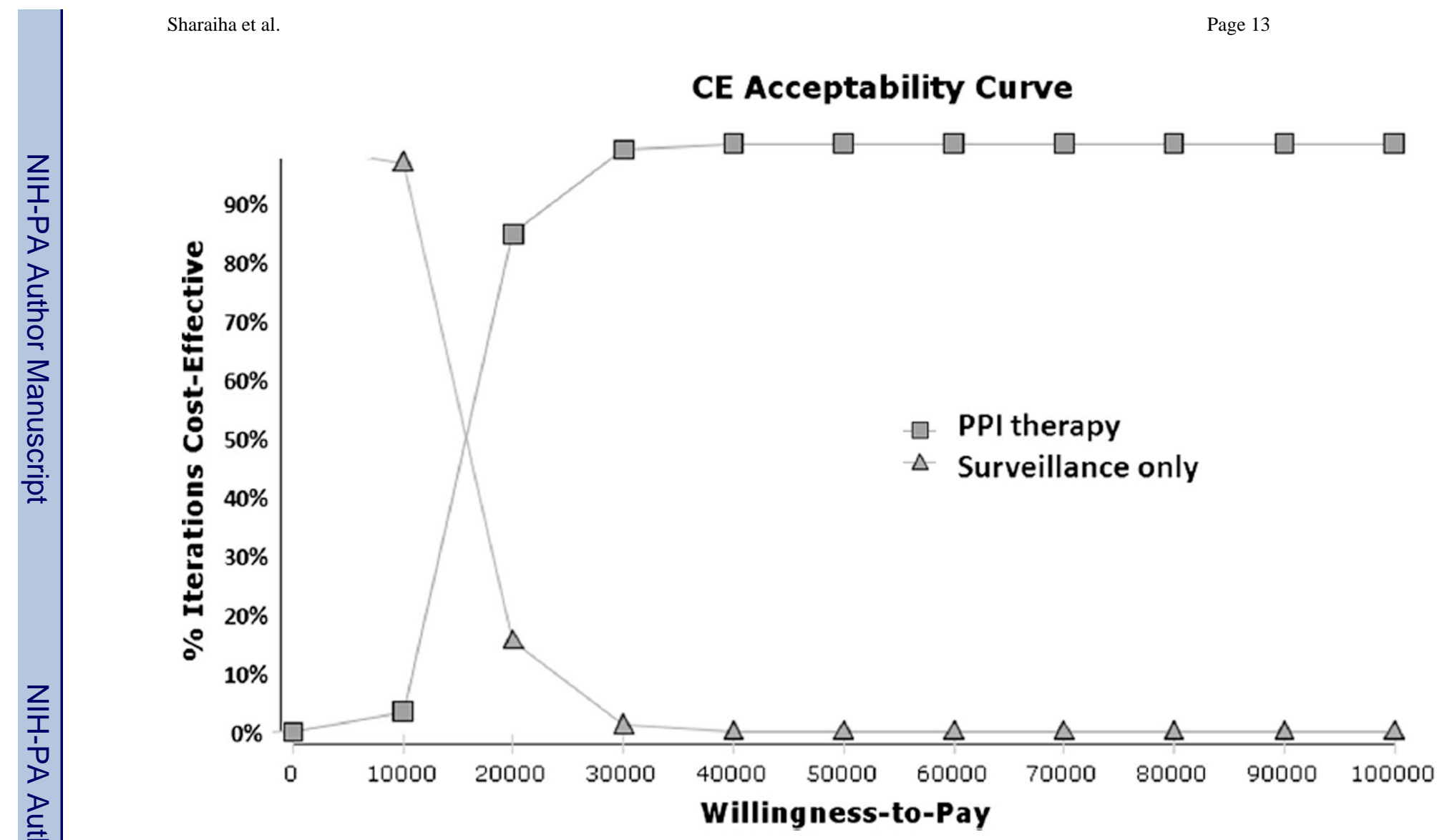

Fig. 2.

Monte Carlo simulation with the optimal strategy stratified by WTP in patients with NDBE. The lines illustrate the proportion of trials in which each strategy was calculated to comprise the optimal strategy, defined as the strategy associated with the greatest QALYS obtainable with a corresponding WTP 


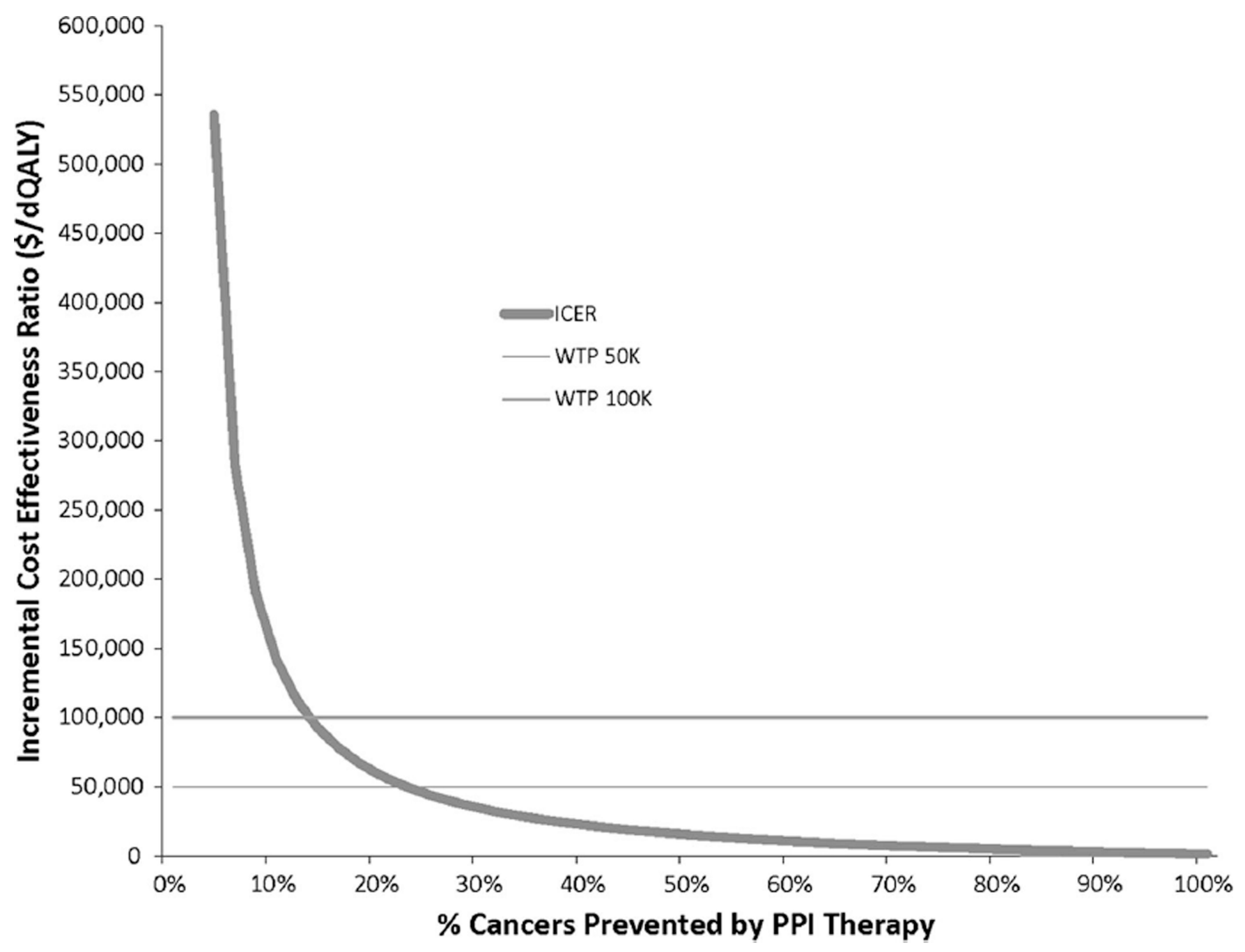

Fig. 3.

One-way sensitivity analysis with risk reduction in chemoprevention with proton pump inhibitors 
Table 1

Estimates of modeled variables

\begin{tabular}{|c|c|c|c|}
\hline Description & Base & Low & High \\
\hline \multicolumn{4}{|l|}{ Cost (2010 US\$) } \\
\hline Cost of cancer & $\$ 49,523$ & $\$ 10,522$ & $\$ 52,620$ \\
\hline Cost of surveillance endoscopy & $\$ 932$ & $\$ 350$ & $\$ 1,100$ \\
\hline Cost of surgical morbidity & $\$ 35,870$ & $\$ 17,230$ & $\$ 70,934$ \\
\hline Cost of cancer palliation & $\$ 1,652$ & $\$ 1,000$ & $\$ 5,066$ \\
\hline Cost of $\mathrm{RFA}^{a}$ & $\$ 22,818$ & $\$ 10,638$ & $\$ 45,600$ \\
\hline Cost of esophagectomy & $\$ 24,994$ & $\$ 10,000$ & $\$ 40,000$ \\
\hline Cost of generic PPI (annually) & $\$ 360$ & $\$ 76$ & $\$ 700$ \\
\hline Cost of bone fracture & $\$ 11,000$ & $\$ 7,800$ & $\$ 19,000$ \\
\hline Cost of $C$. difficile treatment ${ }^{b}$ & $\$ 120$ & $\$ 60$ & $\$ 1,200$ \\
\hline Cost of complicated $C$. difficile & $\$ 10,000$ & $\$ 5,000$ & $\$ 26,338$ \\
\hline Discount rate & 0.03 & 0.00 & 0.05 \\
\hline \multicolumn{4}{|l|}{ Transition rates } \\
\hline ND BE to LGD & 0.03 & 0.01 & 0.08 \\
\hline ND BE to HGD & 0.0055 & 0.0028 & 0.07 \\
\hline ND BE to cancer & 0.0035 & 0.002 & 0.01 \\
\hline LGD to ND BE & 0.50 & 0.45 & 0.80 \\
\hline LGD to HGD & 0.1 & 0.01 & 0.2 \\
\hline LGD to cancer & 0.015 & 0.005 & 0.09 \\
\hline HGD to cancer ${ }^{c}$ & 0.06 & 0.05 & 1.0 \\
\hline HGD to ND BE post-RFA & 0.94 & 0.88 & 0.97 \\
\hline Mortality in unresectable cancer & 0.9 & 0.8 & 1 \\
\hline Mortality from other causes & Varies with age & & \\
\hline \multicolumn{4}{|l|}{ Efficacy (proportion of EAC cases prevented) } \\
\hline PPIs & 0.50 & 0 & 100 \\
\hline \multicolumn{4}{|l|}{ Complications of therapy } \\
\hline Mortality from EGD & 0.000021 & 0 & 0.00005 \\
\hline Mortality from esophagectomy & 0.05 & 0.025 & 0.1 \\
\hline Morbidity from esophagectomy & 0.15 & 0.05 & 0.4 \\
\hline Morbidity from esophagectomy after perforation & 0.2 & 0.1 & 0.5 \\
\hline Perforation with RFA & 0.0005 & 0.0001 & 0.001 \\
\hline Stricture with RFA & 0.025 & 0.01 & 0.05 \\
\hline Rate of fractures in PPI users & 0.00014 & 0.0001 & 0.0009 \\
\hline Rate of fractures in nonusers & 0.0001 & 0.00005 & 0.00015 \\
\hline Rate of $C$. difficile in PPI users & 0.00018 & 0.0001 & 0.00038 \\
\hline Rate of $C$. difficile in nonusers & 0.00008 & 0.00005 & 0.0001 \\
\hline Proportion of complicated $C$ difficile infections ${ }^{d}$ & 0.05 & 0.025 & 0.1 \\
\hline Utilities & & & \\
\hline
\end{tabular}




\begin{tabular}{llll}
\hline Description & Base & Low & High \\
\hline Utility of BE without dysplasia & 1 & 0.79 & 1 \\
Utility of LGD & 1 & 0.8 & 1 \\
Utility of HGD & 0.9 & 0.6 & 1 \\
Utility after RFA & 0.95 & 0.6 & 1 \\
Utility after esophagectomy & 0.8 & 0 & 1 \\
Utility of cancer & 0.5 & 0 & 1 \\
Utility of fracture & 0.79 & 0.7 & 0.95 \\
Utility of C. difficile & 0.998 & 0.997 & 0.999 \\
Utility of complicated C. difficile & 0.88 & 0.8 & 0.95 \\
\hline
\end{tabular}

$a_{\text {Represents cost of three RFA sessions }}$

$b_{14 \text {-day course of metronidazole and/or vancomycin }}$

${ }^{c}$ Base rate for HGD to cancer based on the progression rate of non-responders to RFA

$d_{\text {Proportion of community-acquired C. difficile cases resulting in hospitalization }}$ 


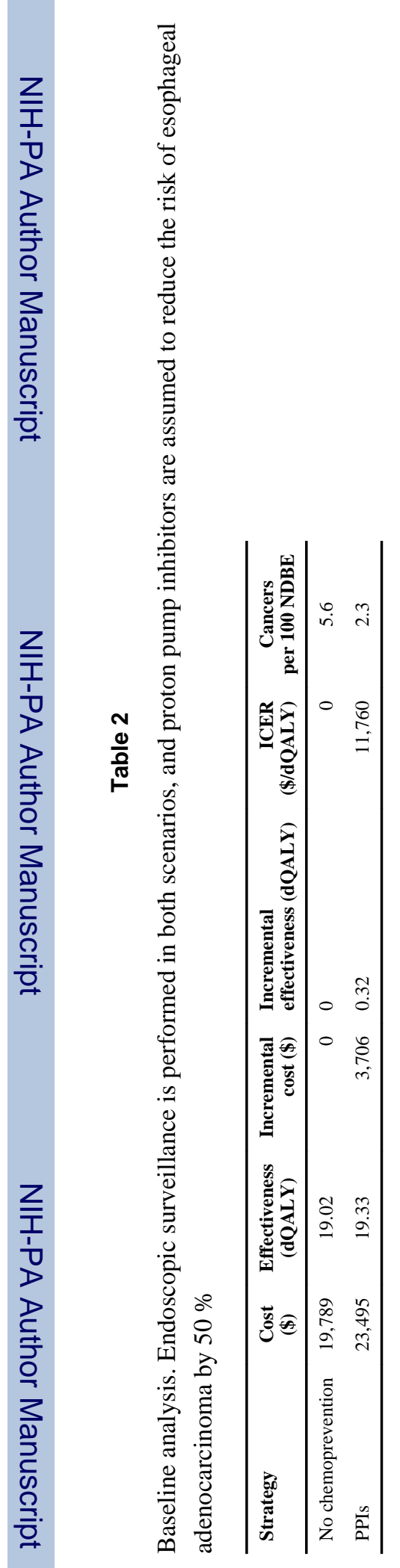

Dig Dis Sci. Author manuscript; available in PMC 2015 February 03. 